\title{
Pre-Lightning Strikes and Aircraft Electrostatics
}

\author{
Joseph Fisher ${ }^{1}$, Paul. R. Hoole ${ }^{2, a}$, Kandasamy Pirapaharan ${ }^{1}$, and Samuel H. Hoole ${ }^{3}$ \\ ${ }^{1}$ Electrical and Communication Engineering Department, PNG University of Technology, Papua New Guinea \\ ${ }^{2}$ Department of Electrical and Electronic Engineering, Universiti Malaysia Sarawak, Malaysia \\ ${ }^{3}$ Department of Electrical and Computer Engineering, Michigan State University, USA
}

\begin{abstract}
An electric storm is a source of electrostatic charge that can induce high current and electric potential on a surface of an aircraft through direct effects. It can also be a source of radiated electromagnetic pulses on an aircraft in flight through indirect effects. Both direct and indirect effects can have adverse effects on flight safety. Thus, it is vital to gain good understanding of the pre-lightning strike and the electrical characteristics of a thunderstorm in order to quantify lightning threats to aircraft. Since lightning parameters are not easily measurable, predictive modeling can be applied to model the pre-lightning strike and aircraft electrostatics. In this paper, we applied the 3D dipole model in predicting the electrostatics build up along an aircraft extremities as it approaches an ambient electric field of a charged cloud. The results give a quantitative evaluation of the threats during pre-lightning strikes and electrostatics buildup on the aircraft. This is vital in designing and coordinating shielding measures to mitigate the threats and to harden the protection systems for aircraft.
\end{abstract}

\section{Introduction}

As an aircraft becomes part of a natural lightning discharge process, the direct and indirect effects due to lightning strikes are recognized as a threat to flight safety. The severity of the threat is heightened further for modern aircrafts made up of composite materials and equipped with the latest digital state of the art technologies. Such modern aircraft design is a doubleedged sword. On one side is the advantage of composite materials that provide cost, weight, and safety advantages, and the ease of flight control through the state of the art of technologies in control, communications, and command systems. While on the other side are the issues of dissipating the electric charges and or current induced away from a non-conductive surface and the susceptibility to electromagnetic interferences (EMI) induced through indirect effects of lightning radiated electromagnetic pulses (LEMPs).

In this paper, we apply a novel and innovative computational tool using the 3-dimensional (3D) dipole analysis to determine the voltage, charges, and electric field induced by lightning on an A380 airbus. We have chosen the airbus to expound on the previous work highlighted in [1].

\section{Thundercloud and aircraft electrostatics}

Cloud electrification process begins with a charge build up and the separation of the charges of opposite polarities

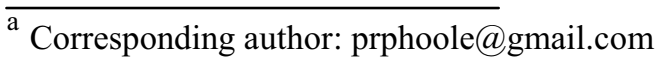

within the cloud [2]. The cloud electrification is simply a result of electrostatic charges of different polarities that buildup within the cloud. There are four major stages of the lightning stroke which are the pre-breakdown, the leader, the attachment process as it reaches an object on the ground, and the return stroke [3].

When an aircraft enters an ambient electric of a thundercloud during the pre-breakdown stages, it will modify the electric field [4]. The entry of an aircraft into an ambient electric field can be regarded as a sudden introduction of a conductor into an electric field which intensifies the local electric fields [4].This enhances the local electric field buildup. The electric field enhancement will reach maxima along the aircraft extremities that are oriented towards the ambient fields. Typically for an ambient electric field of $100 \mathrm{kV} / \mathrm{m}$, the fields at the extremities such as the radome and the tip of the stabilizers, and rudder could be enhanced to $1 \mathrm{MV} / \mathrm{m}$ [5].The charging of the aircraft produces a potential gradient between it and its surroundings. The potential gradient builds up to a sufficient level that corona discharge results. The corona discharges occur at the extremities of the aircraft and initiate a bi-directional leader that connects the cloud charge electrically to ground. There are two distinct phases to lightning-aircraft interaction. First is the development of streamers and leader sets develop at the field enhanced parts of the aircraft. The second phase is the high currents produced by first and subsequent return strokes. The second phase therefore induces the high energy transient current pulse, subsequent re-strikes and the long duration of the slow currents. 


\section{3D modelling of airbus $A 380$ aircraft}

As the potential, the charges, and the electric field along the aircraft surface are all unknown, a novel approach based on Eq.(1) to Eq.(8) was derived in order to analyse the pre-breakdown parameters of aircraft voltage, charges, and the electric field at various altitudes. The aircraft is mapped into dipoles indicated with small dots as shown in Figure 1 and Figure 2. The potential and the charges are computed using the postulation that an object placed in an electric field will assume the potential at that point. Thus, as an aircraft enters a charged thundercloud, it will assume the potential at that point and that all points along the surface will be at equipontential point. This postulation makes the analysis easier to compute knowing the potential coefficients, the cloud charges, and the cloud voltage. A set of equations were derived to compute the charges and the potentials of the dipoles on the aircraft surface.

The dipole placements as illustrated in Figure 1 are for an Airbus A380 near ground at a height of $900 \mathrm{~m}$. The charged cloud center is assumed to be at a height of 1000 $\mathrm{m}$ above ground while the aircraft is almost within the cloud. Note that Figure 1 is not drawn to scale and only shows the two dimensional dipoles D0 to D5 where D0 is the cloud dipole. The 3D arrangement showing the wings, stabilizers, and engines are shown in Figure 2. For convenience and ease of calculation, the aircraft is assumed to be directly below the thundercloud with the mid fuselage taken as the reference point. The dipoles are equally spaced along the fuselage with distances to the right taken as positive while that to the left of the reference point are taken as negative. The aircraft top surface is at $900 \mathrm{~m}$ high while the bottom surface is $890.82 \mathrm{~m}$ indicating a separation distance of the dipoles along the fuselage to be $9.18 \mathrm{~m}$ high. The rudder is protruding another $13.17 \mathrm{~m}$ from the top surface. Figure 2 shows the 3D arrangement of the dipoles.

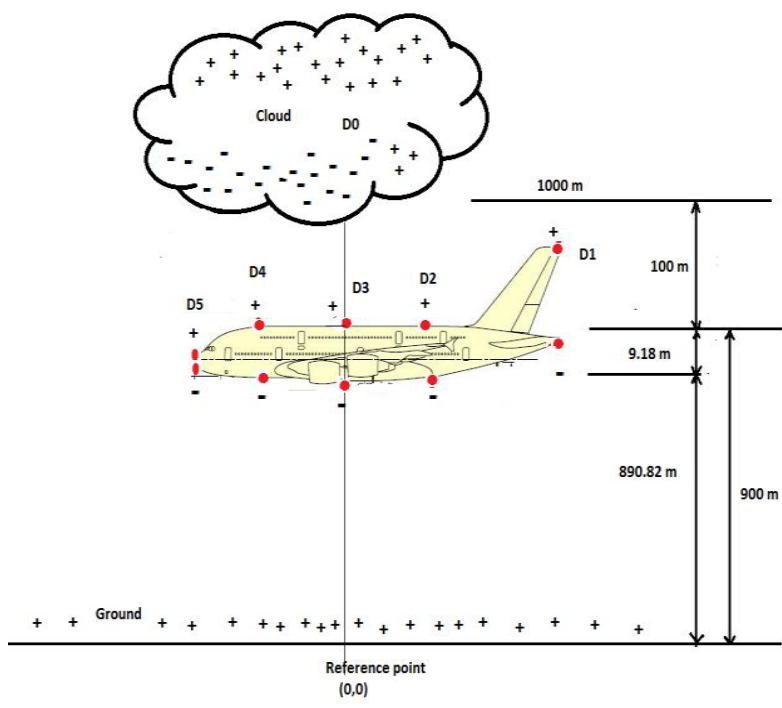

Figure 1 Dipole placements along the aircraft surface [6]
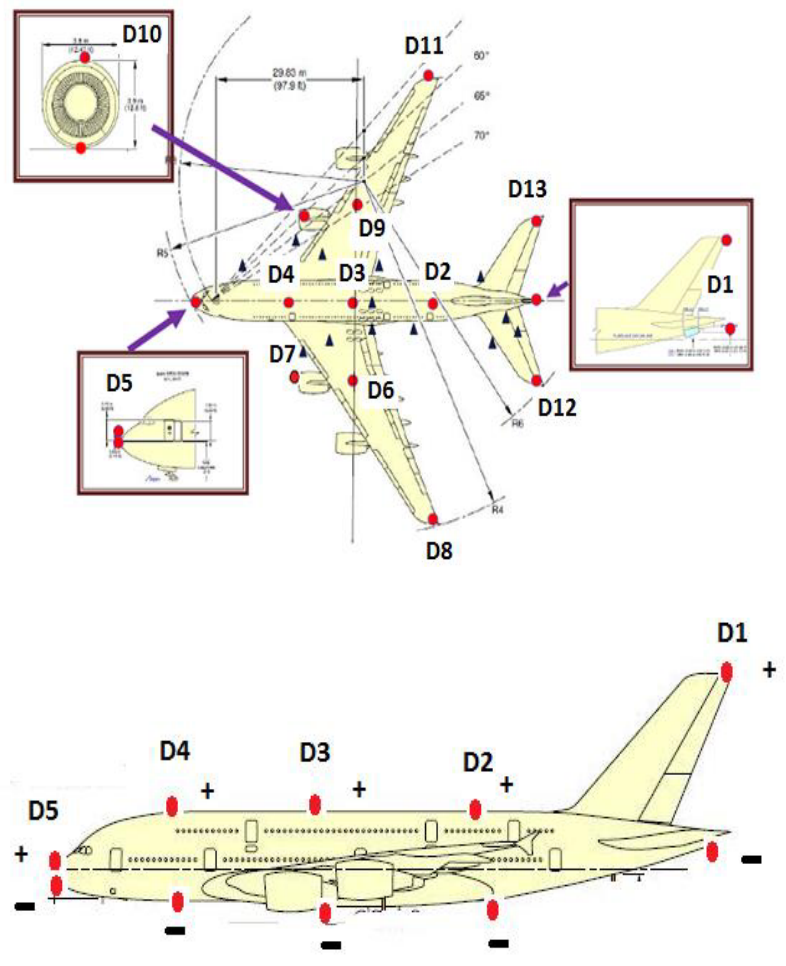

Figure 2 A 3D arrangement of the aircraft dipoles showing the engines and the wings [6]

\section{Computation of airbus A380 parameters}

The 3D dipole model is used to calculate the aircraft voltage, the charge along the aircraft, and the electric field induced by these charges using the equations given in Eq. (1) through Eq.(8). The aircraft voltage is given as

$$
V_{A}=k \cdot q_{A D} \cdot\left(\frac{1}{r_{+}}-\frac{1}{r_{-}}\right)
$$

where $k$ is a constant, $q_{A D}$ is the aircraft dipole charge, and $V_{A}$ is the aircraft voltage. The terms $r_{+}$and $r_{-}$are the distance from the positive and negative mono poles. and their images to a selected point on the aircraft surface. In Eq. (1) $V_{A}$ and $q_{A D}$ are unknown. The only known terms in the equation are the distances from the dipole to a selected coordinate or point on the surface of the aircraft and the separation distances of the mono poles which is determined from the aircraft geometry and the altitude of the aircraft. As the aircraft is at an equipotential surface, $V_{A}$ is the same at all points which makes the analysis easier to solve using the substitution method.

The charge calculation requires the distances of the dipoles and their images and the selected point on the surface of the aircraft. Since the aircraft geometry is in $3 \mathrm{D}$, a three-dimensional distances $(\mathrm{x}, \mathrm{y}, \mathrm{z})$ are determined as defined in the Eq. (2) from the aircraft geometry and its altitude. That is, for a particular point, say $p 1$, on an aircraft surface, where $\mathrm{k}=1$ to 2 where 1 is the positive mono pole and 2 is the negative mono pole that make up 
the dipole, the distance from the center of the dipole to a point $p_{l}$ on the surface of the aircraft is given by Eq. (2). The angle between the mono poles and the point $p 1$ is given by Eq. (3). The same equation is also used in the calculation for the images dipoles, however with different variable used for the aircraft dipoles and the dipole images.

$$
\begin{aligned}
& \operatorname{dis}\left(x_{p 1}, y_{p 1}, z_{p 1}, k\right)= \\
& \sqrt{\left(x_{p 1}-x_{k}\right)^{2}+\left(y_{p 1}-y_{k}\right)^{2}+\left(z_{p 1}-z_{k}\right)^{2}} \\
& \theta_{p 1}\left(x_{p 1}, y_{p 1}, z_{p 1}\right)=\left[\cos ^{-1}\left(\frac{\left(y_{p 1}-y_{k}\right)}{\operatorname{dis}\left(x_{p 1}, y_{p 1}, z_{p 1}, k\right)}\right)\right]
\end{aligned}
$$

Thus, for an aircraft dipole and its image, the general term for the coefficient of potential for the dipole charge is given in Eq. (4):

$$
\begin{aligned}
& q_{A D \text { Coeff }}=\left(\frac{1}{\operatorname{dis}\left(x_{p 1}, y_{p 1}, z_{p 1}, k\right)}\right)-\left(\frac{1}{\operatorname{dis}\left(x_{p 1}, y_{p 1}, z_{p 1}, k\right)}\right)+ \\
& +\left(\frac{1}{\operatorname{dis}\left(x_{p 1}, y_{p 1}, z_{p 1}, l\right)}\right)-\left(1 \frac{1}{\operatorname{dis}\left(x_{p 1}, y_{p 1}, z_{p 1}, l\right)}\right)
\end{aligned}
$$

where $q_{A D c o e f f}$ is the coefficient of the charge due to the dipole $k$ on the surface of the aircraft and its image $l$ within the earth. Thus, the voltage $V_{A}$ at point $p_{l}$ on an aircraft surface due to $n$ number of dipole charges is given by the equation

$$
\begin{aligned}
& q_{A D \text { Coeff } 1} Q_{1}+q_{A D \text { Coeff } 2} Q_{2}+q_{A D \text { Coeff } 3} Q_{3}+ \\
& \ldots \ldots+q_{A D \text { Coeff } n} Q_{n}=4 \cdot \pi \cdot \varepsilon_{0} \cdot V_{A}
\end{aligned}
$$
Eq.(6).

From Eq.(5), the charge $Q_{n}$ is equated as shown in

$Q_{n}=\left(\frac{1}{q_{A D \text { Coeff } n}}\right)\left(\left(4 \cdot \pi \cdot \varepsilon_{0} \cdot V_{A}\right)-\left(\begin{array}{l}q_{A D \text { Coeff } 1} Q_{1}+q_{A D \text { Coeff } 2} Q_{2}+q_{A D \text { Coeff } 3} Q_{3}+\ldots \\ \ldots+q_{A D} \operatorname{coeff}{ }_{n-1} Q_{n-1}\end{array}\right)\right)$

A similar procedure is applied for the next point $p_{2}$ on the surface of the aircraft to obtain the voltage equation as shown in Eq.(7).

$$
\begin{aligned}
& q_{A D \text { Coeff } 1} Q_{1}+q_{A D \text { Coeff } 2} Q_{2}+q_{A D \text { Coeff } 3} Q_{3}+ \\
& \ldots \ldots+q_{A D \text { Coeff } n} Q_{n}=4 \cdot \pi \cdot \varepsilon_{0} \cdot V_{A}
\end{aligned}
$$

The process of solving a set of linear equations by substitution method is applied here by equating for a charge $Q_{n}$ in the equation for a point $p_{n}$ in terms of the other $\mathrm{Q}$ variables and substituting that value in the next equation for point $\mathrm{p}_{\mathrm{n}+1}$. The procedure is repeated for $(n+$ 1) points thus eliminating the charges (Q) terms. The final equation is simply a single equation comprising of the charge coefficients and the aircraft voltage $V_{A}$ which is the only unknown term. Thus, from the computed aircraft voltage, the charges and the electric fields can be easily determined. The electric field is computed using Eq. (8). The computational process is quite tedious as it requires $n+1$ sets of equations $n+1$ points for $n$ number of mono poles.

$$
E=\frac{(k \cdot q) \cdot \bar{u}}{r^{2}}
$$

\section{Simulation of pre-breakdown electric fields}

The application of the computational method in calculating the aircraft voltage and electric fields and the surface charges for an A380 airbus at various altitudes and distances away from a -50 MV charged clouds are shown in Table 1 through Table 3 . Table 1 is for an airbus A380 aircraft at an altitude of $900 \mathrm{~m}$ just below a negatively charged cloud center of $1000 \mathrm{~m}$ altitude. The aircraft voltage computed by the substitution method is $42.6227 \times 10^{6}$ Volts. This is high as expected as the aircraft is almost within the charged cloud center of a potential of $-50 \mathrm{MV}$. The dipole electric fields calculated along the A380 aircraft shows high electric fields at the rudder tip of $1.394 \times 10^{6} \mathrm{~V} / \mathrm{m}$ and the left horizontal stabilizer of $1.137 \times 10^{6} \mathrm{~V} / \mathrm{m}$. Both these fields are within the specified breakdown electric field of $3 \times 10^{6} \mathrm{~V} / \mathrm{m}$ as defined in [2] for dry air at sea level. These two extremities with the highest electric fields are most likely to initiate a bidirectional leaders into the charged cloud center to trigger a lightning flash connecting through the other extremities to ground. With a high electric field at the rudder tip, the most likely swept area would be along the fuselage connecting the radome to ground. That is, the rudder tips becomes the entry point while the radome becomes the exit point as defined in the normative zoning standards [7].

Similarly, the results shown in Table 2 is that for an airbus A380 at an altitude of $900 \mathrm{~m}$ but $1.5 \mathrm{~km}$ away from the charged cloud center. The aircraft potential is $1.4247 \times 10^{6}$ Volts. Comparing the dipole electric fields calculated, it is high for the rudder tip of $2.566 \times 10^{5} \mathrm{~V} / \mathrm{m}$ and the left and right horizontal stabilizers of $1.338 \times 10^{5}$ $\mathrm{V} / \mathrm{m}$ and $1.186 \times 10^{5} \mathrm{~V} / \mathrm{m}$ respectively. The electric fields are below the breakdown level however, as the aircraft 
approaches the charged cloud, the electric field will reach the breakdown level of $3 \times 10^{6} \mathrm{~V} / \mathrm{m}$ as defined by [2]. Table 3 is the result for the A380 airbus at an altitude of $600 \mathrm{~m}$ below the charged cloud center of $1000 \mathrm{~m}$. The aircraft potential is $-9.3 \times 10^{6}$ Volts. The electric fields at the extremities appear to be low to cause a breakdown in the field to trigger lightning flash.

Table 1. Dipole charges and electric fields for airbus A380 at $900 \mathrm{~m}$ altitude.

\begin{tabular}{|l|l|l|}
\hline \multicolumn{3}{|c|}{$\begin{array}{l}\text { Cloud altitude: } 1000 \mathrm{~m} \\
\text { Computed Voltage: }-42.6227 \times 10^{6}\end{array}$} \\
\hline & $\begin{array}{l}\text { Dipole Charge } \\
\text { (C) }\end{array}$ & $\begin{array}{l}\text { Dipole } \\
\text { Electric Field } \\
\text { (V/m) }\end{array}$ \\
\hline Dipole Location & -0.556 & $4.546 \times 10^{5}$ \\
\hline Cloud (D0) & 0.03357 & $1.394 \times 10^{6}$ \\
\hline Rudder tip (D1) & $-1.29067 \times 10^{-4}$ & $6.452 \times 10^{3}$ \\
\hline Mid-right fuselage (D2) & $-6.48594 \times 10^{-4}$ & $5.102 \times 10^{3}$ \\
\hline Center fuselage (D3) & $-1.96159 \times 10^{-4}$ & 706.507 \\
\hline Mid-left fuselage (D4) & $-1.09003 \times 10^{-3}$ & $2.113 \times 10^{3}$ \\
\hline Radome (D5) & $-1.68948 \times 10^{-3}$ & $1.173 \times 10^{4}$ \\
\hline Mid-left wing (D6) & $1.19192 \times 10^{-3}$ & $4.676 \times 10^{3}$ \\
\hline Left wing engine (D7) & 0.02353 & $1.309 \times 10^{5}$ \\
\hline Tip left wing (D8) & $4.89565 \times 10^{-3}$ & $2.699 \times 10^{4}$ \\
\hline Mid right wing (D9) & $4.06858 \times 10^{-4}$ & $1.445 \times 10^{3}$ \\
\hline Right wing engine (D10) & $9.86454 \times 10^{-3}$ & $3.93 \times 10^{3}$ \\
\hline Tip right wing (D11) & -0.02284 & $1.137 \times 10^{6}$ \\
\hline (D12) & -0.02117 & $2.764 \times 10^{5}$ \\
\hline & & \\
\hline & & \\
\hline
\end{tabular}

Table 2. Dipole charges and electric fields for Airbus A380 at $900 \mathrm{~m}$ altitude and $1500 \mathrm{~m}$ away from the charged cloud center.

\begin{tabular}{|l|l|l|}
\hline \multicolumn{3}{|c|}{$\begin{array}{c}\text { Cloud altitude: } 1000 \mathrm{~m} \\
\text { A380 Aircraft altitude: } 900 \mathrm{~m} \text { but } 1500 \mathrm{~m} \text { away from } \\
\text { cloud center }\end{array}$} \\
Computed Voltage: $-1.42047 \times 10^{6}$ Volts \\
\hline Dipole Location & $\begin{array}{l}\text { Dipole Charge } \\
\text { (C) }\end{array}$ & $\begin{array}{l}\text { Dipole Electric } \\
\text { Field (V/m }\end{array}$ \\
\hline Cloud (D0) & -0.556 & $2.123 \times 10^{3}$ \\
\hline Rudder tip (D1) & 0.05503 & $2.566 \times 10^{5}$ \\
\hline $\begin{array}{l}\text { Mid-right } \\
\text { fuselage (D2) }\end{array}$ & $-6.29337 \times 10^{-4}$ & $9.998 \times 10^{3}$ \\
\hline
\end{tabular}

\begin{tabular}{|l|l|l|}
\hline $\begin{array}{l}\text { Mid fuselage } \\
\text { (D3) }\end{array}$ & $-1.38886 \times 10^{-6}$ & 290.099 \\
\hline $\begin{array}{l}\text { Mid-left } \\
\text { fuselage (D4) }\end{array}$ & $-1.38592 \times 10^{-7}$ & 6.688 \\
\hline Radome (D5) & $-1.77916 \times 10^{-6}$ & 15.67 \\
\hline $\begin{array}{l}\text { Mid-left wing } \\
\text { (D6) }\end{array}$ & $-9.31133 \times 10^{-8}$ & 2.449 \\
\hline $\begin{array}{l}\text { Left wing } \\
\text { engine (D7) }\end{array}$ & $5.12937 \times 10^{-6}$ & 189.167 \\
\hline $\begin{array}{l}\text { Tip left wing } \\
\text { (D8) }\end{array}$ & $1.202258 \times 10^{-4}$ & 655.562 \\
\hline $\begin{array}{l}\text { Mid right wing } \\
\text { (D9) }\end{array}$ & $1.55047 \times 10^{-6}$ & 20.566 \\
\hline $\begin{array}{l}\text { Right wing } \\
\text { engine (D10) }\end{array}$ & $5.66717 \times 10^{-6}$ & 105.314 \\
\hline $\begin{array}{l}\text { Tip right wing } \\
\text { (D11) }\end{array}$ & $1.01073 \times 10^{-4}$ & 396.936 \\
\hline $\begin{array}{l}\text { Left horizontal } \\
\text { stabilizer (D12) }\end{array}$ & -0.02817 & $1.338 \times 10^{5}$ \\
\hline $\begin{array}{l}\text { Right horizontal } \\
\text { stabilizer (D13) }\end{array}$ & -0.0 .02814 & \\
\hline
\end{tabular}

Table 3. Dipole charges and electric fields for Airbus A380 at $600 \mathrm{~m}$ altitude.

\begin{tabular}{|l|l|l|}
\hline \multicolumn{3}{|c|}{$\begin{array}{c}\text { Cloud altitude: } 1000 \mathrm{~m} \\
\text { Computed Voltage: -9.3 } \times 10^{6} \mathrm{~m} \text { Volts }\end{array}$} \\
\hline Dipole Location & Dipole Charge (C) & $\begin{array}{l}\text { Dipole } \\
\text { Electric Field } \\
\text { (V/m) }\end{array}$ \\
\hline Cloud (D0) & -0.556 & $3.105 \times 10^{4}$ \\
\hline Rudder tip (D1) & $-1.41643 \times 10^{-4}$ & $5.882 \times 10^{3}$ \\
\hline Mid-right fuselage (D2) & $-3.64386 \times 10^{-6}$ & 182.152 \\
\hline Mid fuselage (D3) & $-1.42385 \times 10^{-5}$ & 128.558 \\
\hline Mid-left fuselage (D4) & $-4.22488 \times 10^{-5}$ & 15.217 \\
\hline Radome (D5) & $-2.19604 \times 10^{-5}$ & $4.257 \times 10^{3}$ \\
\hline Mid-left wing (D6) & $-3.7381 \times 10^{-5}$ & 259.623 \\
\hline Left wing engine (D7) & $2.34651 \times 10^{-5}$ & 92.061 \\
\hline Tip left wing (D8) & $3.43659 \times 10^{-4}$ & $1.911 \times 10^{3}$ \\
\hline Mid right wing (D9) & $1.0453 \times 10^{-4}$ & 576.379 \\
\hline $\begin{array}{l}\text { Right wing engine } \\
\text { (D10) }\end{array}$ & $6.03978 \times 10^{-6}$ & 21.449 \\
\hline Tip right wing (D11) & $5.60395 \times 10^{-5}$ & 223.284 \\
\hline
\end{tabular}




\begin{tabular}{|l|l|l|}
\hline $\begin{array}{l}\text { Left horizontal } \\
\text { stabilizer (D12) }\end{array}$ & $2.07244 \times 10^{-5}$ & $1.032 \times 10^{3}$ \\
\hline $\begin{array}{l}\text { Right horizontal } \\
\text { stabilizer (D13) }\end{array}$ & $5.45472 \times 10^{-5}$ & $1.16610^{3}$ \\
\hline
\end{tabular}

\section{Conclusion}

The application of the 3D dipole computational analysis in predicting lightning aircraft pre-breakdown electrostatics has been observed. Among the significant observations in this research, are the high electric field buildup at the aircraft extremities as an aircraft approaches the charged cloud center. The results obtained shows the electric fields at the aircraft extremities reach the breakdown electric field of $3 \times 10^{6} \mathrm{~V} / \mathrm{m}$. This highlights an important quantitative understanding of the phenomena of pre-lightning strike and aircraft electrostatics that can be applied in protection and shielding coordination to mitigate the effects of lightning strike on commercial and military aircraft. Modern aircraft industries are employing non-metallic structures and highly digital and computerized control technologies in aircraft command and control systems that are susceptible to failures and damages if no extra protection against severity of lightning are in place. Thus, aircraft industries need an improved definition of the threats that lightning poses in order to continue to drive the protection standards that can render safety of aircraft.

\section{References}

1. J. Fisher, P.R.P. Hoole, K. Pirapaharan, and S. R. H. Hoole, Applying a 3D Dipole Model for Lightning Electrodynamics of Low-Flying Aircraft. IETE Journal of Research, Vol.61, No.2, (2015)

2. D.R. Poleman. On the Sciences of Lightning: An Overview, Scientific Technical Publication No:56. Royal Meteorological Institute of Belgium, (2010)

3. Miranda et al. 2008. Occurrence of Characteristic Pulses in Positive Ground Lightning in Brazil. 19 International Lightning Detection Conference, Tucson USA, (2008).

4. P.R.P. Hoole, S. Thirikumaran, H. Ramiah, J. Kanesan, and S.R.H. Hoole, 2014. Ground to Cloud Lightning Flash and Electric Fields: Interaction with aircraft and Production of Ionospheric Sprites. Journal of Computational Engineering, Vol.2014, Article ID 869452. http://dx.doi.org/10.1155/2014/869452, (2014)

5. D. Morgan, C.J. Hardwick, S.J. Haigh, and A.J Meakins, The Interaction of Lightning with Aircraft and the Challenges of Lightning Testing, Aerospace Lab Journal. 5, ALO5-11, pp. 1-10, (2012)

6. Airbus A380,Aircraft Characteristics Airport and Maintenance Planning, Airbus Technical Data and Support and Services, (2014).

7. G. Sweers, B. Birch, and J. Gokcen, Lightning Strikes: Protection, Inspection, and Repair. Boeing AERO Magazine, Issue 48_Quater 04, pp 19-28, (2012). 